\title{
التقييم الدينامى وعلاقته بالمهارات التحليلية والابداعية بئية
}

\author{
|عراد \\ الباحثة/ روحية عاطف محى اللديز محمد \\ باحثة ماجستير
}

إسر افـ

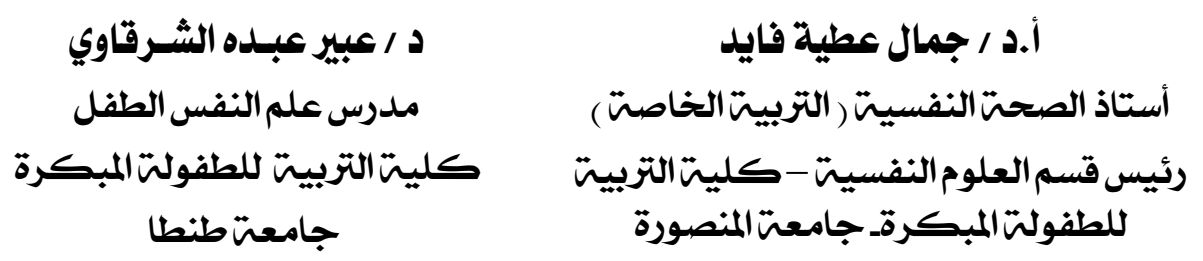

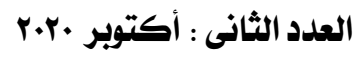


التقييم الدينامى وعلاقته بالمهارات التحليلية والابداعية

روحيت عاطف محى الدين محمد *

$$
\begin{aligned}
& \text { المحور الأول / التقييم الدينامى : } \\
& \text { (1) مفهوم التقييم الدينامى : }
\end{aligned}
$$

هو تقييم لحيز النمو المكن للمتعلم ، ويقصد به المسافة بين مستوى النمو الحقيقى الذى يصل اليه الفرد بمفرده من خلال حل المشكلات ، ومستوى النــــو

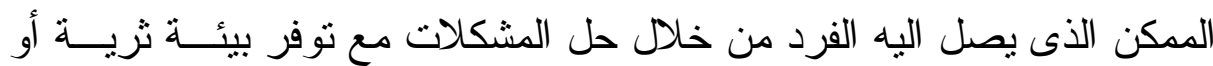
وسيط يساعد على هذا النمو بحيز النمو الممكن • (Vygotsky , 1978 ) ويعرفه (محمد طه ،T . . : : ) ) أن الثقييم الدينامى يعد نوعا من ادماج

التدريب و التغذية المرتدة ، واستثارة قدر من التعلم فى موقف الاختبــار ذاتــهـ ،

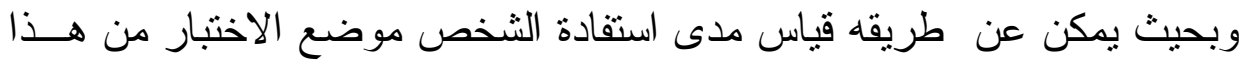

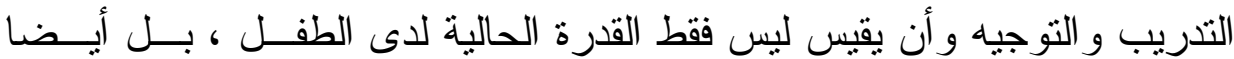
قدرته على الاستفادة من خبر ات التعلم التى قد تتاح له ، ومدى قدر اته للتعـديل و التحسين ، ويتضمن تعلما فى نطاق موقف الاختبار نفسه .

$$
\text { (Y) التقييم التقليدي و التقييم الدينامي المعرفي : }
$$

يهتم النقييم التقليدي بدرجة وارتقاء النمو العقلي ويركز على نتائج النـــو السابقة بينما يهتم النقييم الدينامي المعرفي بأسلوب و عمليات النمو العقلي ويركز لانياء

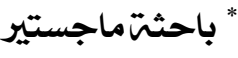

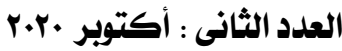


على مقدمات النمو في المستقبل، وفي التقييم التقليدي يهتم بدرجة وارتقاء النـــو

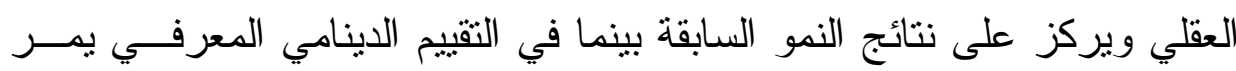

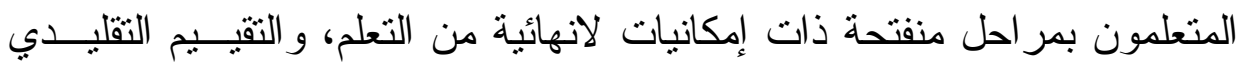

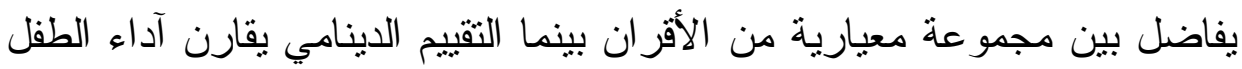

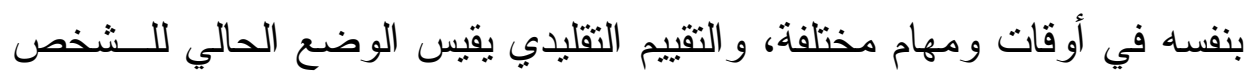

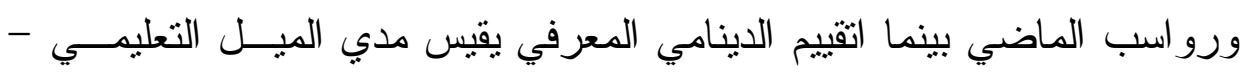

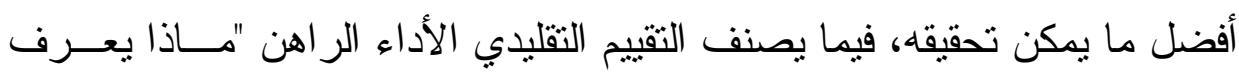

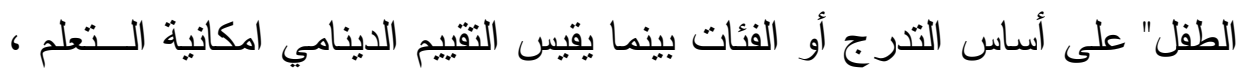

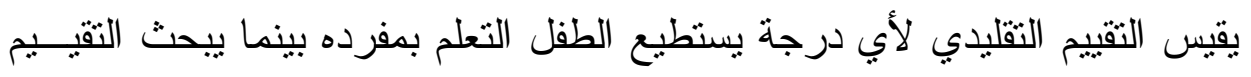

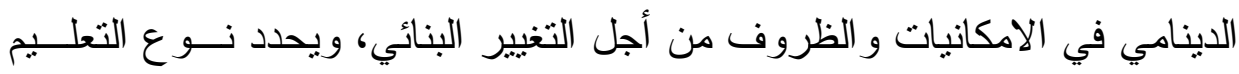

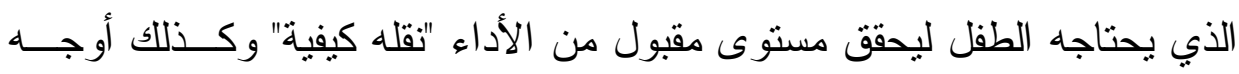

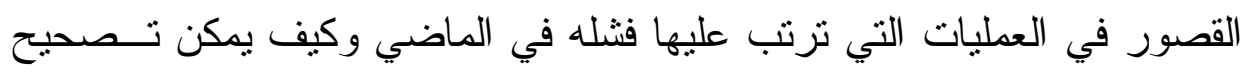

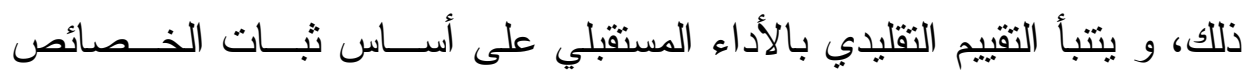

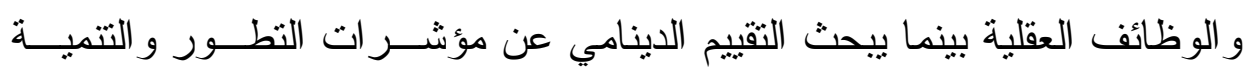

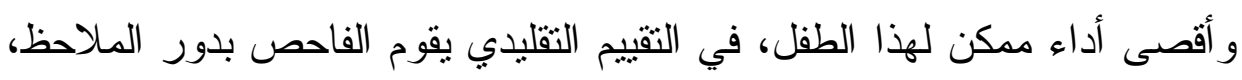

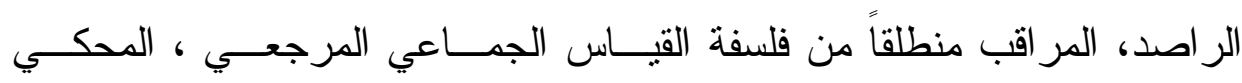

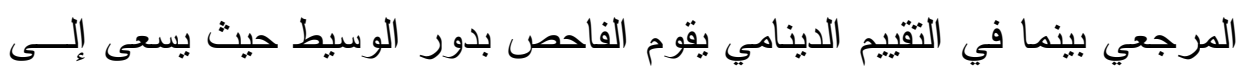

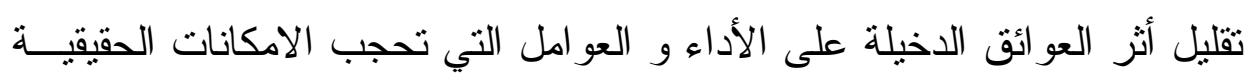
التي يسعى القياس الدينامي إلى تقديرها(Vygotsky, 1978) الهدف من التقييم التقليدي هو القياس و التزتيب و التقييم بينما الهدف مسن

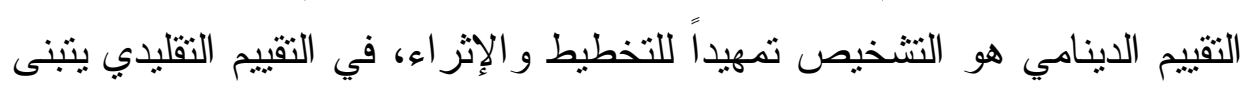

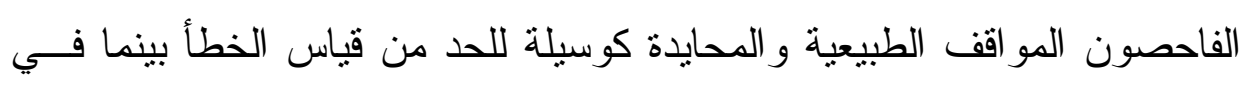


القياس الدينامي يتدخل الفاحص في عملية التقييم ، و في النقييم التقليدي يعطى

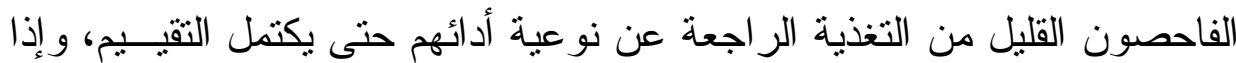
فعل عدا ذلك يهدد نتائج الإختبار الحقيقية بينما في التقييم الدينامي هنــاك شـــكل معين من التغذية الراجعة (مساعدة الوسيط) و هذا هو جوهر عملية التقيبم( صفاء

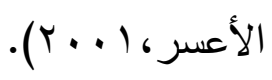

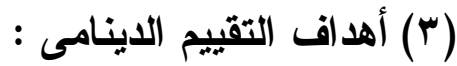
ا ـ قياس مدى امكانية تغيير اداء الفرد من خلال عرض مو اد التقييم التسى

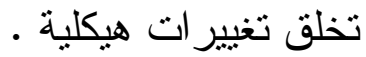

r. قياس القيود و الظروف المحيطة بالبيئة التى يمكن أن يحدث التعديل . r. تحديد مقدار المساعدة اللازمة للحصول على تتغير فى الفرد . ع. تقييم أهية أو مغزى التعديل فى اداء الثخص .

ْ. ملاحظة وتسجيل الاساليب المفضلة لاى الفـرد لتجهيـز نقـــاط القــوة و الضعف على حد سو اء . ) Saunders,J,J.2018;21 كما تتشير الاعسر الى أن الهدف الاساسى للتقييم الــدينامى لــبس هــــ

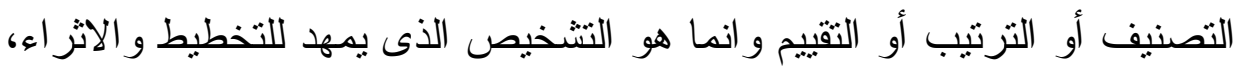
حيث أنه يسعى لتوفير بيئة ثرية بالمثير ات مركز ها المفحوص بكل ما يقوم بــهـ

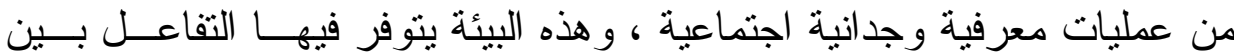

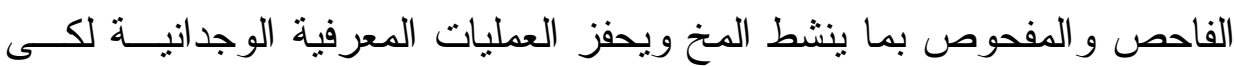
تعمل بقدر مالديها من وسع معرفى ، حيث يقوم الفــاحص بتـــعيم الاجابــات

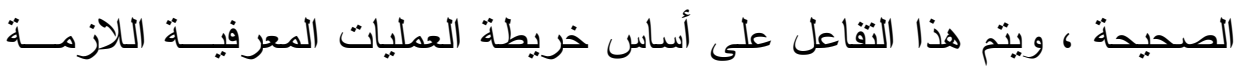


لتجهيز المعلومات فى المهام المختلفة ـ ويتم على أساسها تقدير جوانسـب القــوة و الضعف لدى المفحوص ، ومقدار ما يحتاجه من اثراء وحيز النمو الممكن لديه

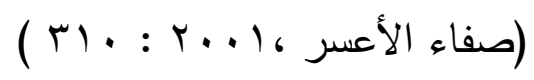
( ) أهمية التقييم الاينامى :

1. تشخيص قدر ات الفرد وليست تقييمها باختبار ات الاستخبار ات المعياريسـة

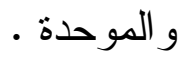

r. تحرى استر اتيجيات التعلم وأى الطرق تعطى فرصا أفضل للتعلم . r. يوفر التعلم فى اطار الاختبار وهو طريقة مفيدة لتقييم الامكانيات . ؛. اظهار ما لدى المتعملين من قدر ات كامنة .

0. يقدم النقييم الدينامى تمثيلا لا لقدرات الطفل بالمقارنة مع نظائرهم ولكن Spero, J, M. 2012; ) مع قدر اته مقارنة عبر الزمن ومع تأثثر التعلئي

$$
\text { : خصائص التقييم الدينامى : (o) }
$$

• التقييم الدينامى ليس اجر اء بل مجموعة من الاجر اءات و التقييمات . • المقيم ذو نأثير ويندخل بهدف احداث تغيير فى مسنوى المتعلم . • يركز التقييم على اجر اءات المتعلم لحل المشكلات بما فيها تلك التى تعيـق التعلم. • استجابة المتعلم للتنخل أو مدى الاستفادة منه هى نقطة التميز فى التقبــيم

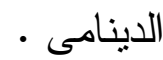


يوفر معلومات حول ما اذا كان التنخل ناجحا ( طور أو غير فى المتعلم )

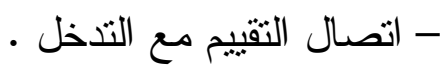
• شكل التقييم غالبا ما يكون بطريقة الاختبار القبلى و البعدى . (?) (؟) مراحل التقييم الدينامي هناك نوعان من الثقييم الدينامي أحدهما طويل الأمد و الثاني قصير الأمد،

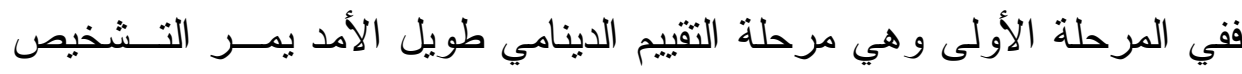
الدينامي بثلاث مر احل يمر بها الدفحوص سيتم التعرض لها في النقاط التالية : 1-مرحلة الاختبار القبلى : فحص الوضع المعرفي عنــــ المفحـوص قبــل

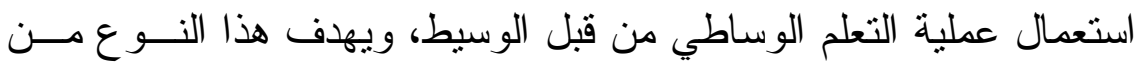

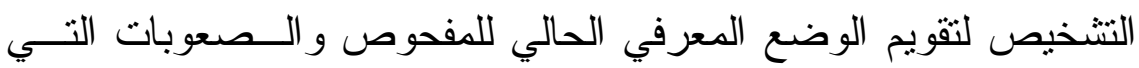

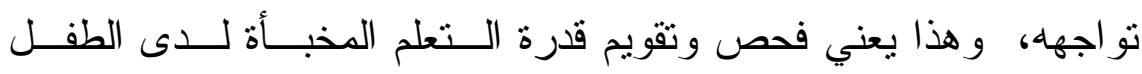
و الطريقة المناسبة لتطويره . r-مرحلة التعلم الوساطى : حيث يعمل الفاحص علـى تحسـين القــرات العقلية الضعيفة الموجودة عند المفحوص من خلال استعمال عملية التعلم

$$
\text { • الوساطي }
$$

ب-مرحلة الاختبار البعدى : فصص الوضع المعرفي الخاص بــالمفحوص

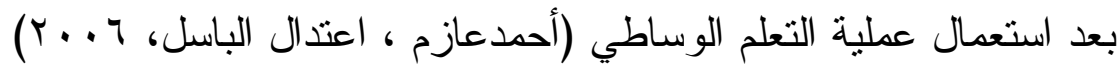
و الطريقة الثانية من النقييم الدينامي و التي تسمى تقيــيم دينـامي قــصير

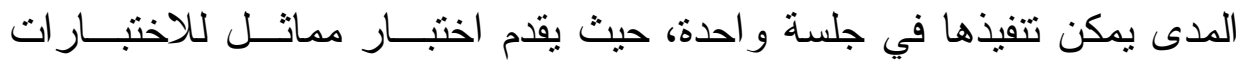
التقليدية ولكن مع تقديم المساعدة و التوجيه عند وجود صعدة صعوبات، و لا يتم الانتقال 
عند مستوى أعلي إلا عند حل جميع أسئلة المستوي الأدني، إما إذا لم يتم حـل

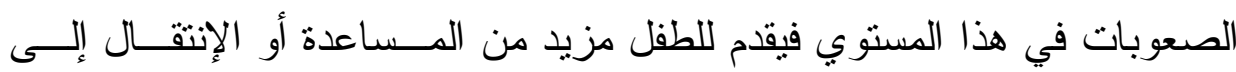

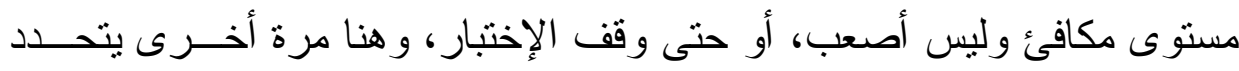

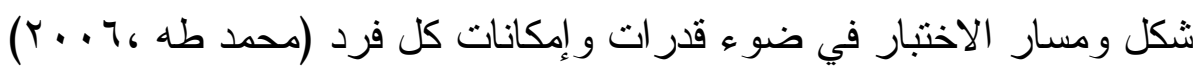
وفى هذا الصدد أنتبتت نتائج در اسة بايكك وكيم أن التقييم الدينامى طويــل

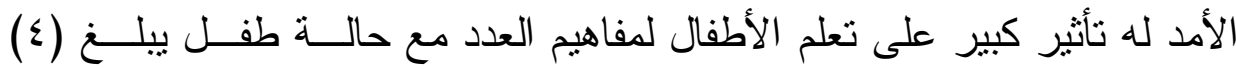

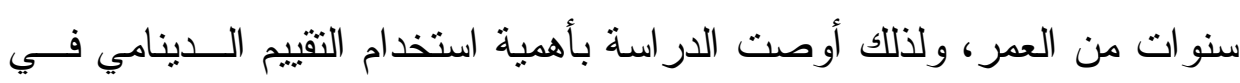
تقييم التعليم على نطاق واسع لتتمية العمليات المعرفية لدى الأطفال

( Beak,S \& Kim,K, 2011)

( Kapantzoglou,M, وكما استخدمت در اسة كابانتزوجلو و آخــرون

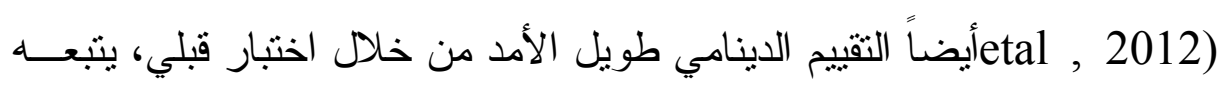

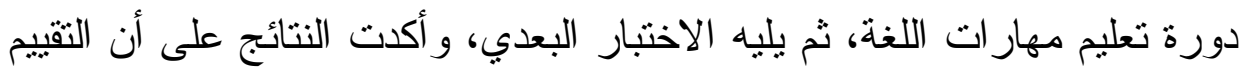

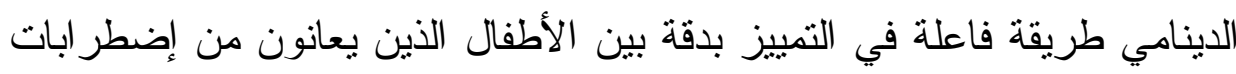

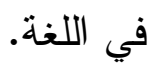

\section{المحور الثانى / المهارات التحليلية : (1) مفهوم مهارات التفكير التحليلى :}

مهارة التقكير التحليلى هى القدرة على تحديد الفكرة أو المشكلة وتحليلهـــا

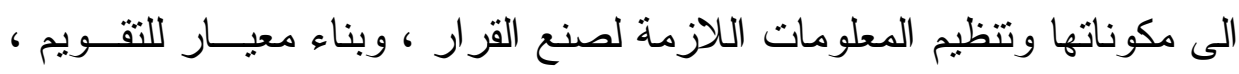

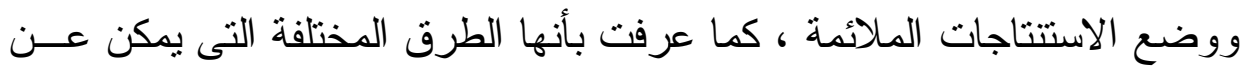


طريقها تقسيم الثئ الى أجزاء وبعد ذلك استخدام الأجزاء لادر الك الثنئ الأصلى

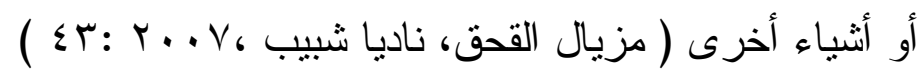

: أهمية التفكير التحليلى (r) يوضح ( أيمن عامر ، . . . . ، 0) أهمية التفكير التحليلى فى أنه يسساعد الفرد على : (1)

1 - عزل المشكلة الأساسية عن باقى المشكلات . ז- ادر الك العلاقات الدقيقة التى تربط عناصر المشكلة . r- استخدام أكبر عدد من الحواس فى ادر الك وفهم المشكلة . ع - تحديد المشكلة فى اطار السياق المحيط بها .

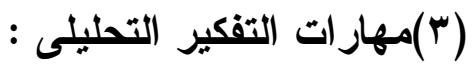
أولا - فهم المشكلة :

يتم دراسة وتحديد المشكلة بتعمق لمعرفة جوهر المشكلة الحقيقى ولــــس

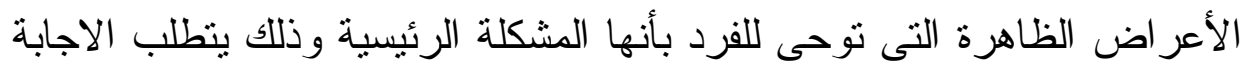

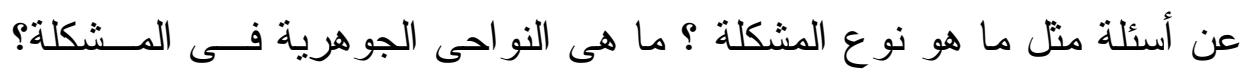

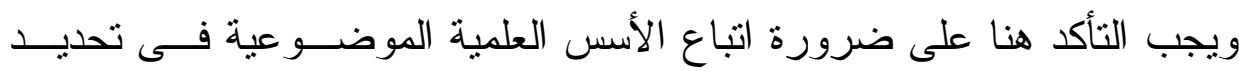
المشكلة بشكل دقيق . ثانيا- تحليل الموقف المشكل :

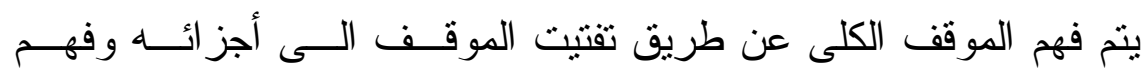
العناصر لكل جزء وكيف تعمل هذه العناصر معا للموقف الكلى لفههــهـ بــشكل 
أفضل هذة العملية تسمى (مهار ات التحليل ) التى ينبغى علـى كـل صــف ان

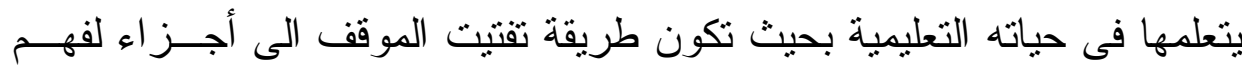

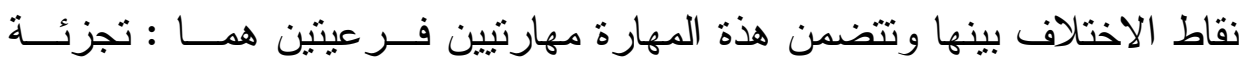

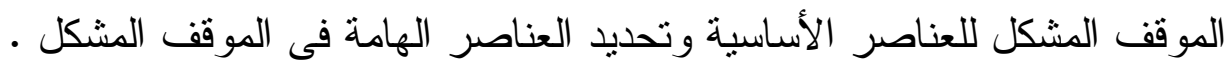
ثالثا- تحديد الهدف أو الأهداف :

قد يكون الهدف عاما ، وقد تكون هناك مجموعة من الأهداف المتعـددة

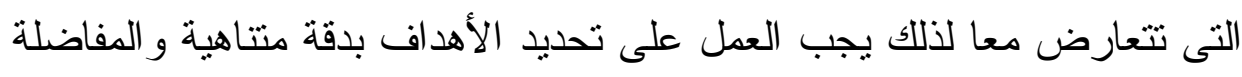

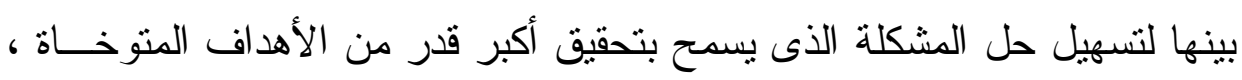

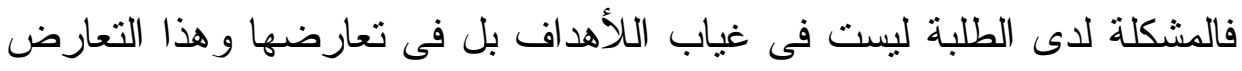

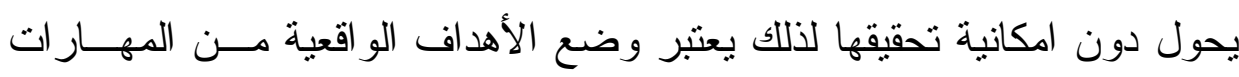

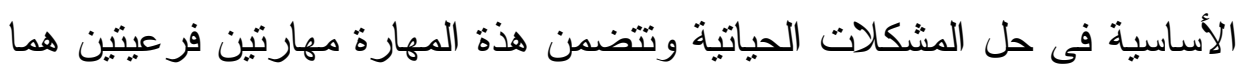
: مهارة تقييم امكانية تحقق الأهداف ، ومهارة ترنيب الأولويات فى الأهداف .

$$
\text { رابعا- التفكير بمتطلبات الموقف المشكل : }
$$

فالتفكير فى المنطلبات الأساسية للموقف المشكل ، التى تتمتل فى القـدر

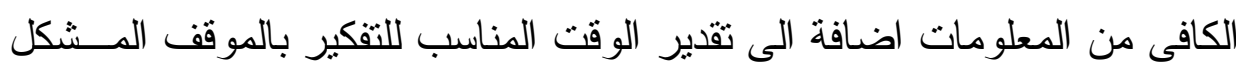

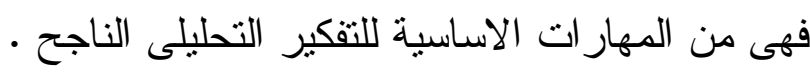
خامسا- مقارنة عناصر الموقف المشكل : وتتضمن القدرة على المقارنة بين شيئين أو فردين أو فكرتين أو أكثر من

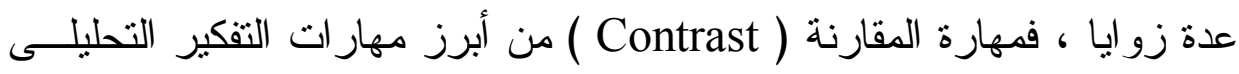

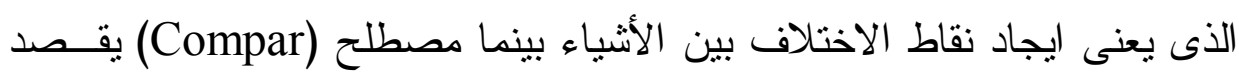


به ايجاد أوجه التشابه بين الأشياء ، فالفرد يعمل على البحث عن نقاط التـشابه أو لا ثم البحث عن نقاط الاختلاف ، وفى هذه المهارة تعمل على وصف الأشياء

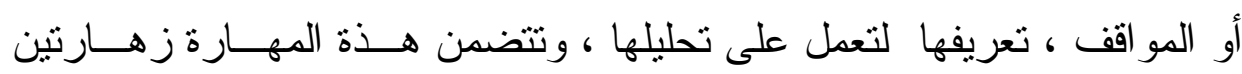
فر عيتين هما: تحديد نقاط التشابه و الاختلاف بين عناصــر الموقــف المــشكل وتحديد أهمية العناصر ذات الصلة بالموقف المشكل.

سادسا- توليد البدائل :

ويقصد بهذه المرحلة التقصى و التحرى عن الحلول الممكنة للمشكلة التـى

تم تشخيصها بدقة فى مرحلة سابقة وتعتمد هذه المرحلة على قدرة الفــرد علـىى التحليل و الابتكار لايجاد حلول جديدة بالاعتماد على التجارب السابقة ومعلومات لتهات

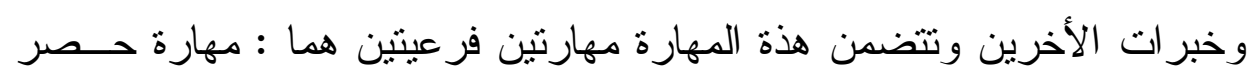
البدائل المتوفرة ومهارة البحث عن بدائل جديدة .

\section{سابعا- ترثيب البدائل والمفاضلة بينهما:}

حيث يو اجه الفرد الذى يفكر تفكيــر ا تحليليــا صــعوبة تتمثتـل فــى أن

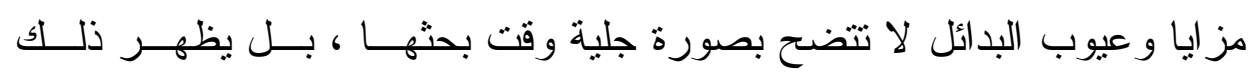

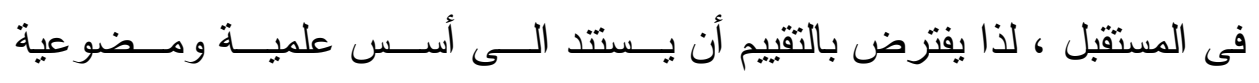
وتوخى الحذر و التأنى عند ثقييم البدائل حيث لابد من الأخذ بعين الاعتبار العديد

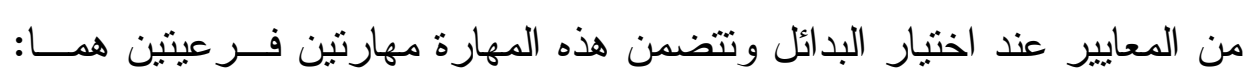
مهارة تحديد معايير الحكم على البدائل ، ومهارة تقدير الأوزان لمعايير ترتيــبـ - البدائل مائل 
ثامنا- تقييم البدائل الأفضل: فى ضوء المر احل السابقة يمكن للفرد الذى يفكر تفكير ا تحليليا أن يكـون

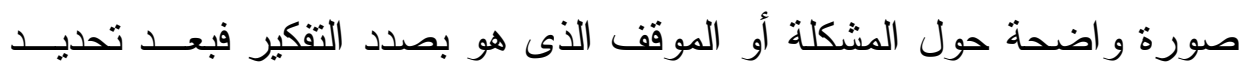

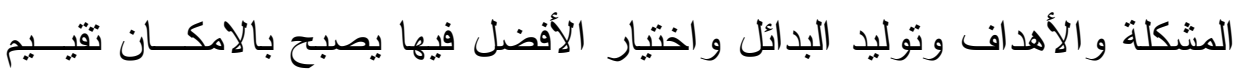

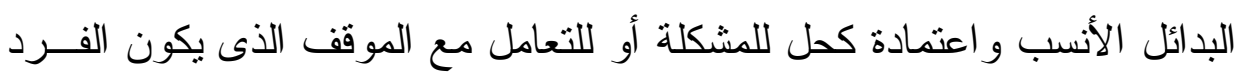
بصدد در استه ، وتتمل هذه المهارة مهارتين فرعيتين هما : مهارة تحديد أفضل البدائل ، ومهارة وضع خطة بديلة .

\section{تاسعا- تفسير وتوضيح حل الموقف المشكل :}

ان دور الفرد الذى يفكر تفكير ا تحليليا لا ينتهى بمجـرد اختيـار البـديل

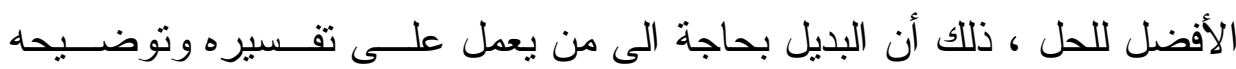

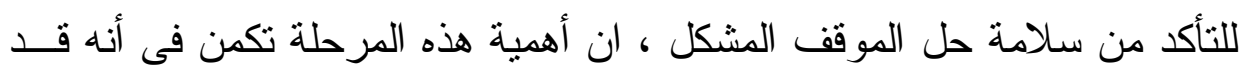

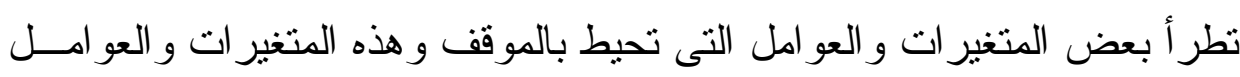

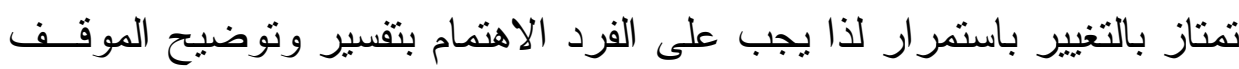

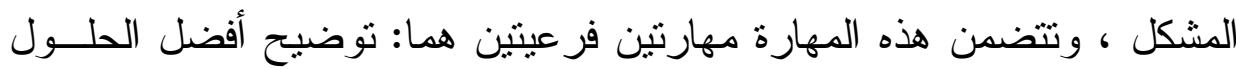

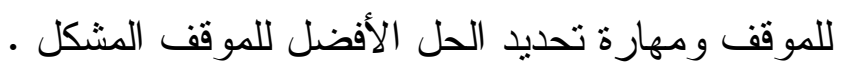
عاشر ا- التنفيذ واصدار الحكم: ان التنفيذ واصدار الحكم ييقيان هدفا منشودا حتى يتم التأكد منهمــــــودور

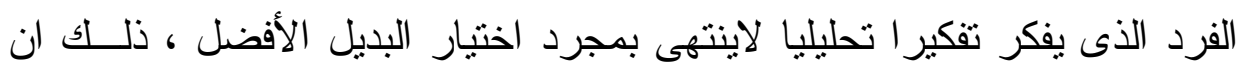

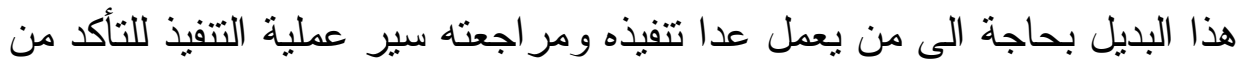

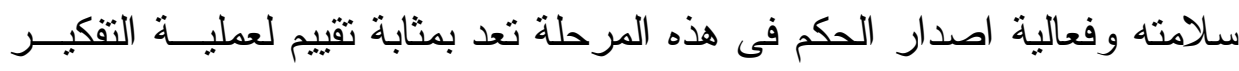

$$
\text { العدد الثانى : أكتوبر •r.r. }
$$


التحليلى وتحديد مدى جودتها وفاعليتها ، وتتــضمن هــذه المهــارة مهــارنين فر عيتين هما : مهارة تحديد الية تتفيذ الحل ومهارة نقــد نتــائج تتفيــذ الحــل

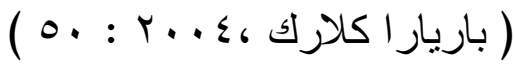

$$
\begin{aligned}
& \text { المحور الثالث / المهار ات الابداعية : } \\
& \text { (1)مفهوم مهار ات التفكير الابداعى : }
\end{aligned}
$$

يعرف بأنه " العملية الذهنية التي تستخدمها للوصول الى الافكار و الرؤى الجديدة ، أو التي تؤدي الى الدمج و التأليف بين الافكار او الاتثياء التي يعتبــر

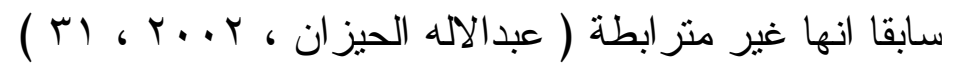

و يعرفه جروان بأنه : " نشاط عقلي مركب و هادف توجهه رغبة قويـــة

في البحث عن حلول أو التوصل الى نواتج أصيلة لم تكن معروفة ســابقا " ، و يصوف التفكير الابداعي بأنه تفكير منتج أو تقكيـر متباعــــ أو تفكيـر جـانبي

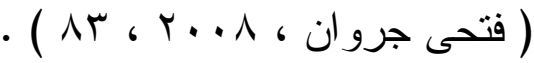

$$
\begin{aligned}
& \text { (Y)مهار ات التفكير الابداعى : }
\end{aligned}
$$

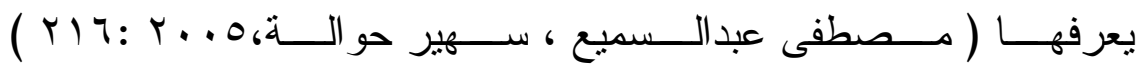

بأنها" مجموعة المهار ات العقلية التى تستخدم عند قيام الفرد بــــى عمليــة مــنـ

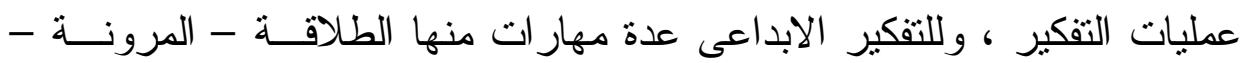

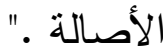

ا- الحساسية للمشكلات Sensitivity to Problems: وتعني القدرة علـى رؤية المشكلات ورؤية جو انب النقص و العيوب في الموقف أو البيأـــة أو

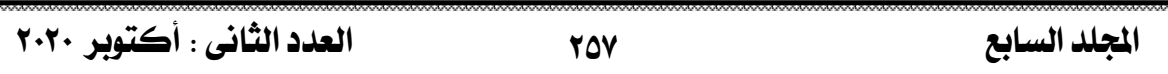


الأشياء و العادات أو النظم، و اكتشاف المشكلة بعد الخطوة الأولى للبحــث عن حلول للمشكلة إما بإضافة معرفة جديدة أو إدخال تعديلات وتحسينات على الموقف موضوع المشكلة. r- المرونة: تعني إنتاج أفكار جديدة عن طريــق تحويــل اتجــاه التفكيــر

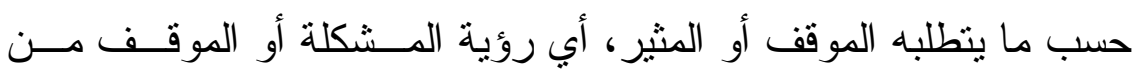
زو ايا مختلفة، ومــن أثـــكال المرونـــة: المرونـــة التلقائيــة و المرونـــة التكيفية .

ب- الطلاقة: تعني القدرة على إنتاج عدد كبير من الأفكار اللفظية أو الأدائيــة أو البدائل أو المشكلات المفتوحة النهاية أو الاستعمالات أو المتر ادفــات عند الاستجابة لمثير معين، و الطلاقة هي عملية اســتدعاء المعلومـات ومفاهيم وخبر ات تم تعلمها وتخزينها لدى الفرد، وللطلاقة أنـــواع نـــــر منها: طلاقة الأشكال، طلاقة الكلمات أو الطلاقة اللفظية، الطلاقة الفكرية أو طلاقة المعانى، طلاقة التداعي . ع- الأصالة: تعد الأصسالة من أكثر المهـــار ات ارتباطــاً بالإبـــداع و التقكيــر

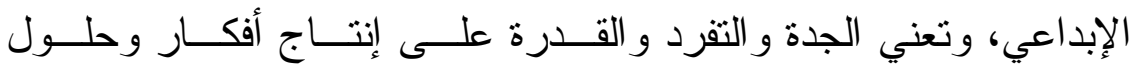
ومقترحات جديدة غير مألوفة ه- الإفاضة Elaboration: وتعني القدرة على إضـــاقة تفـــيلات جديــدة ومتتو عة تساهم في تحسين وتجميل الأفكار البسيطة أو الاستجابة العاديــة وتجعلها أكثر تطور اً و فائدة وجمالاً لئا 
7- التخيل: يعد أعلى مستويات الإبداع و أندر ها، ويقوم على انطلاق الأفكــار

بحرية دون الأخذ بالاعتبار الارتباطات المنطقية أو الو اقعيــة للأفكـار.

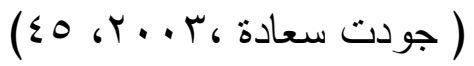

$$
\begin{aligned}
& \text { (ץ) أهمية مهارات التفكير الابداعى : }
\end{aligned}
$$

يشير فيجوتسكي إلى أن جميع البشر وحتى الأطفــال الــــغار يكونـــون

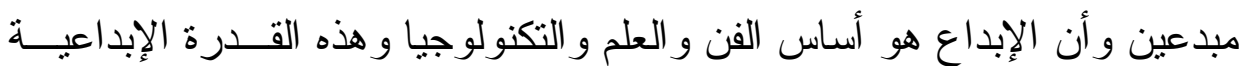

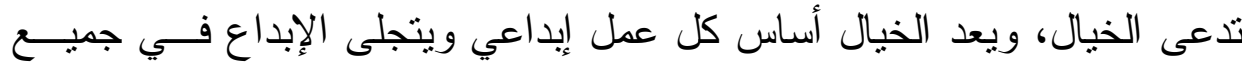

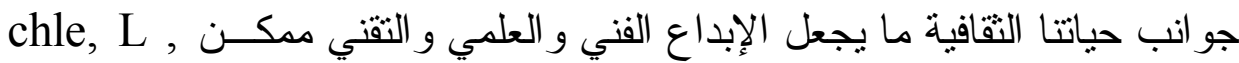
(Mi 1976) و التفكير مهارة تكتسب ويتم التدرب عليها بالأنسشطة الإبداعيــة

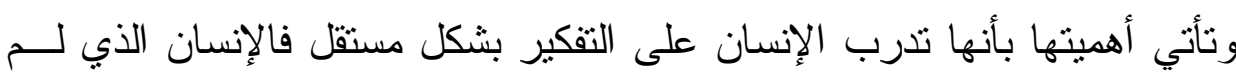

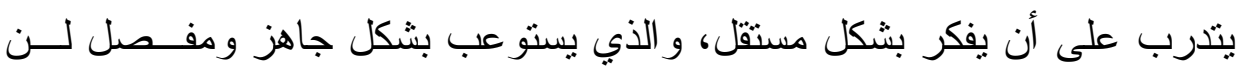

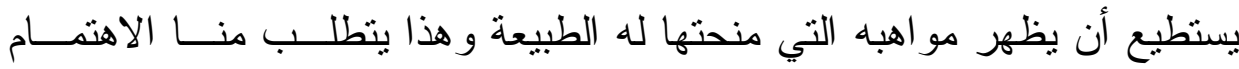

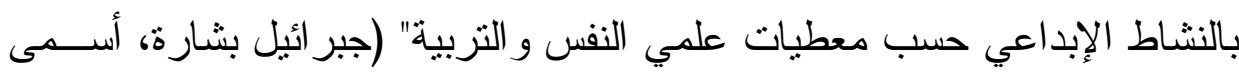

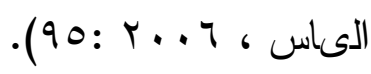

فالمبدعون هم أمل الأمة و القادرون على النهوض بذو اتهم و مجتمعـاتهم الى ارقى درجات التقام و الرقي الإنساني ، فاهتمام المجتمعات البشرية بالابداع

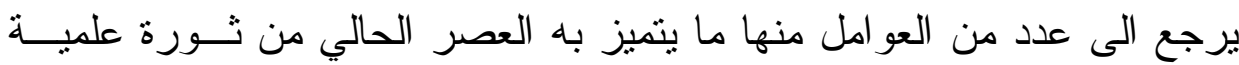
تكنولوجية و تفجير في المعرفة و تطور سريع و تتامي حاجات الفكر الاساسـية و الاجتماعية الى حاجات تقديم الافكار الجديدة غير النمطية، فالمعلم يعد محور أساسي في تتمية التفكير لدى الطلاب لإعداد الفرد بما بمكنه من واجهة الحياة و لهائه 
متطلبات العصر باعلية كذلك هيئ المعلم المناخ الذي يقوي ثقة المتعلم بنفسه او يدمرها ، يقوي روح الإبداع او يقتلها ، ومن هنا يتضح أهمية الاهتمــام بتتميــة

$$
\begin{aligned}
& \text { مهار ات التفكير و لا سيما التفكير الابداعي ( جودت سعادة ، . . r ) } \\
& \text { (ع) جوانب التفكير الابداعى : }
\end{aligned}
$$

ينظر للابداع من ثنلاث جو انب هى : الابداع كقدرة ، الابـــداع كاتجــاه ،

$$
\text { الابداع كعملية ، وفيما يلى عرض لكل منها : }
$$

ا - الابداع كقدرة : فالابداع هو القدرة على تصور شئ جديد واختر اعه ، او

توليد أفكار جديدة عن طريق مزج أو تغيير الأفكار الموجودة ، ويمكـن

القول بأن هذه القدرة موجودة لدى كل فرد ولكن بنسب متفاوتة ، بحسـب

$$
\text { اختلاف الظروف و المو اقف . }
$$

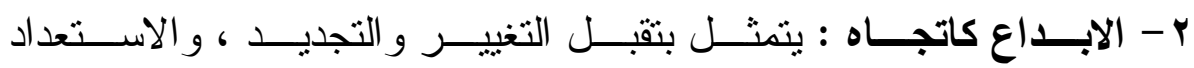

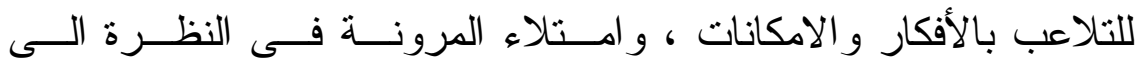

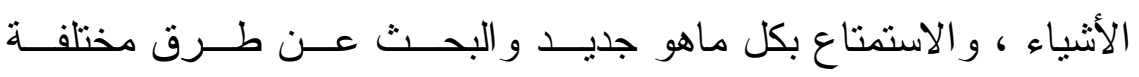

ب- الابداع كعمليــة : ويكون الابداع عملية عندما يعمل الأشخاص المبدعون

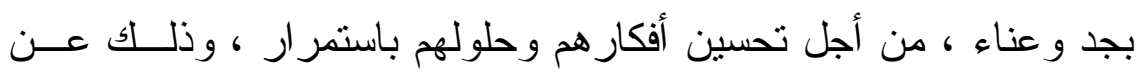
طريق اجر اء تغير ات تدريجية وتحسينات مستمرة على أعمالهم ( عــنان

$$
\text { العتوم و آخرون ، V . . . ، ب r r ) . }
$$




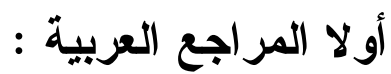

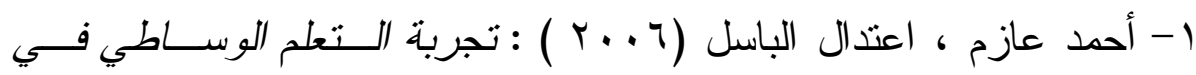

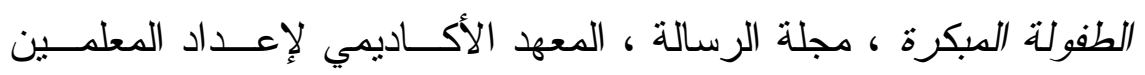

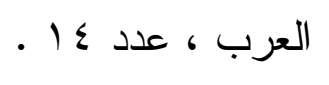

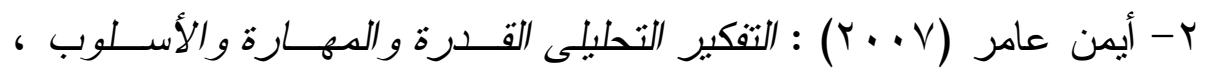

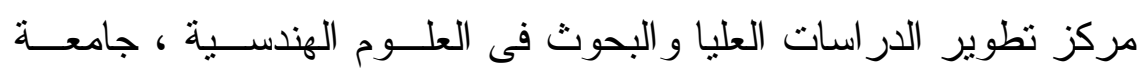

$$
\text { القاهرة . }
$$

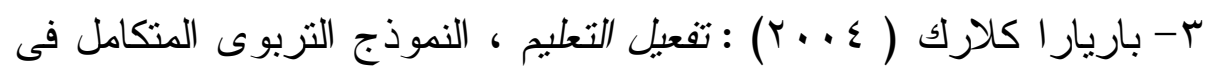

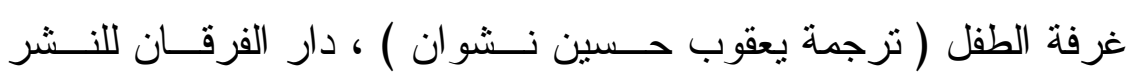

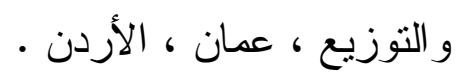

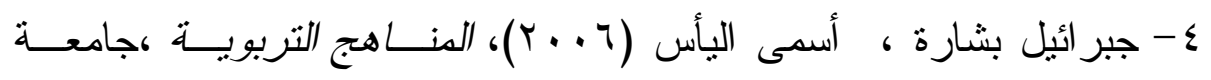

$$
\text { دمشق، دمشق. }
$$

0- جودت أحمد سعادة ( r . . ) : ت تدريس مهار ات التفكير - مــع مئسات

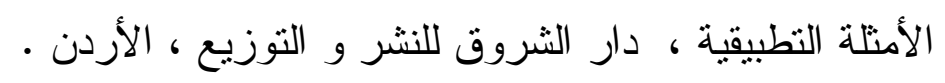

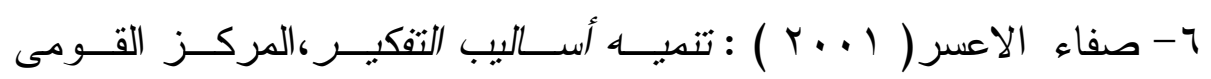

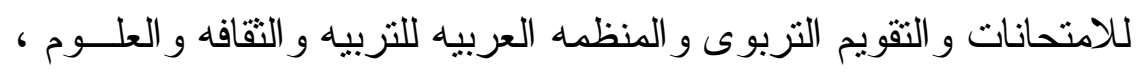

$$
\text { القاهرة . }
$$


V- عبدالإله الحيزان ( r . . r ) : لمحات عامة في التفكير الابداعي ، مكتبة الملك فهد الوطنية ، الرياض ، المملكة العربية السعودية .

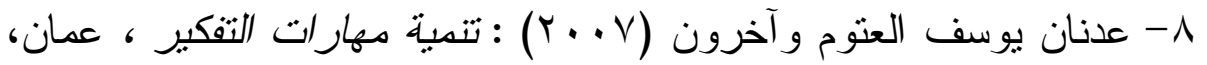

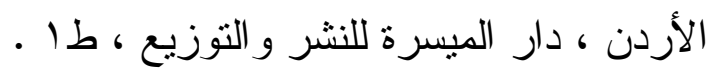

9- فتحى عبدالرحمن جروان (1 . . ب): الدوهبة والتفوق والابداع ، عمان ،

دار الفكر للنشر و النوزيع ، طب جرون

•

نقدية، مجلة عالم المعرفة ، الكويت

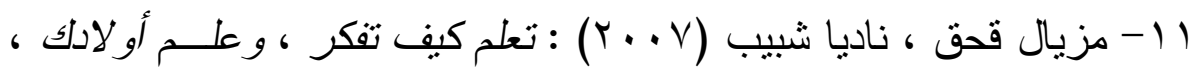

دار العلم للنشر و التوزيع ، لبنان

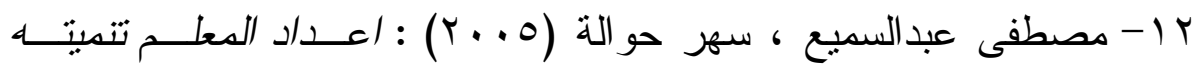

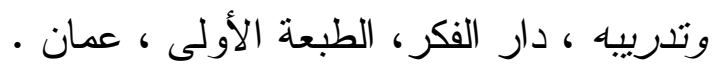

\section{ثانيا المراجع الأجنبية : مانية}

1-Baek ,S, \& Kim, K ( 2011 ) : The Effect of Dynamic Assessment Based Instructions on Children's Learning, International Journal of Language Studies ( IJLS ), vol 5 , number (1), $125-140$.

2-Kapantzoglou , M ,Restrepo ,M\&Thompson,M (2012) : Dynamic Assessment of Word Learning Skills, Identifying Language Impairment in Bilingual Children, Language, Speech, and Hearing Services in Schools, Vol 43, number (1), $81-96$. 
3-Michle, Louise (1976) : La craetivite, 2 me edition, PUF , France, p14.

4-Spero , J , M (2012) : Comparison between a dynamic assessment procedure and the WMLS - Rin distinguishing languge abilities among Hispanic children in ferst grad, Doctoral dissertation Rutgers university -Graduate school of applied and professional psychology .

5-Saunders , J , J ( 2018) : Age Related Differences in the dynamic assessment of working memory when predicting reading and math out comes, Doctoral dissertation, UC Riverside .

6-Vygotsky, L.S (1978) : Mind in Society: The Development of Higher Psychological Processes, Cambridge, MA: Harvard University Press. 